\title{
My Baby Bird - Living With Type 1 Diabetes: A Phenomenological Analysis
}

Catherine Aquino-Russell, BScN, MN, Ph.D., University of New Brunswick, Moncton Canada Roger Russell, BSc (Agr), MBA, Ph.D., Crandall University Moncton, New Brunswick Canada Allison Russell, BSc (Kinesiology), New York Chiropractic College, Seneca Falls, USA Catrina Russell, BSc (Geology), MSc Geology student, University of New Brunswick, Fredericton, Canada

\begin{abstract}
"This is a life-changing experience for all of us. You have one child with diabetes and your whole family has diabetes" (Isenberger, 2009, p. 134). More than two million Canadians have diabetes; $10 \%$ live with type 1 diabetes, involving the pancreas not being able to produce insulin (Canadian Diabetes Association, 2009). The incidence of type 1 diabetes is greater than has previously been described (Karvonen et al, 2000). One longitudinal phenomenological study used interviews for data collection to uncover family members' lived experiences when their children (aged 9-14) were diagnosed with type 1 diabetes (Wennick \& Hallström, 2006, 2007; Wennick, Lundqvist, \& Hallström, 2009). Interestingly, Balfe (2009) wrote, "young adults with type 1 diabetes are a "forgotten group" (p. 128).
\end{abstract}

The purpose of our ongoing phenomenological research is to explore the experiences of young adults and their family members. We are having challenges recruiting potential participants (individuals and their family members) to write about and email their experiences living with or having a young adult member who lives with type 1 diabetes; however, we have one description of a lived experience written by a young adult which is so eloquent, that we wanted to share it with others. We have completed a Giorgi (2009; Giorgi \& Giorgi, 2003) descriptive phenomenological analysis guided by the humanbecoming theory for nurses (Parse, 1998) and have related the findings to the literature. This paper includes a moving metaphorical illustration about what it is like for one young adult to live with type 1 diabetes.

Keywords: Type 1 Diabetes; Lived Experience; Phenomenological; Humanbecoming; Young Adult; Nursing

\section{INTRODUCTION}



his is a life-changing experience for all of us. You have one child with diabetes and your whole family has diabetes" (Isenberger, 2009, p. 134). More than two million Canadians have diabetes, and $10 \%$ of them live with type 1 diabetes, which involves the pancreas not being able to produce insulin (Canadian Diabetes Association, 2009). The incidence of type 1 diabetes is greater than has previously been described in the literature (Karvonen, et al, 2000). "Diabetes is a lifelong, life-threatening condition that has a significant impact on children's and parents' lives" (Marshall, Carter, Rose, \& Brotherton, 2009, p. 1703). Literature describing a longitudinal phenomenological study has been found which used interviews as a data collection strategy to uncover family members' lived experiences when their children (aged 9-14) were diagnosed with type 1 diabetes (Wennick \& Hallström, 2006, 2007; Wennick, Lundqvist, \& Hallström, 2009). It has been suggested that "conducting child- and parent-centered qualitative research allows exploration of the perceptions and understanding the meaning of living with type 1 diabetes as ascribed by those living with it (Marshall, et al., 2009). Interestingly, Balfe (2009) wrote, "young adults with type 1 diabetes are a "forgotten group" (p. 128). Therefore, research developed to ascertain a deeper understanding of the lives and experiences of young adults and their family members will enable more focused delivery of nursing care to meet their specific needs as well as enhancing support and treatment from other health care providers. 


\section{PURPOSE}

The purpose of our ongoing phenomenological research is to focus on the experiences of young adults and their family members. The objectives of our study are: to build on our programs of research describing the meaning of this lived experience (Aquino-Russell, 2003; Russell, 2007); to build on Parse's (1998) humanbecoming theory for nursing; to present the findings to health care professionals and the community in creative ways to promote understanding of the lived experience; and to involve our family as co-researchers, since we have recently been introduced to living with type 1 diabetes ourselves.

Currently, we are having challenges recruiting potential participants in family groups to write about: their experiences living with type 1 diabetes, or what it is like for them having a family member who lives with type 1 diabetes; however, we have one description of a lived experience, written by the third author of this paper, which is so eloquent, that we wanted to share it with others.

\section{METHODOLOGY: RESEARCH METHOD AND THEORETICAL UNDERPINNINGS}

We have completed a Giorgi (Giorgi \& Giorgi, 2003; Giorgi, 2009) descriptive phenomenological analysis on the data description as seen through the lens of the humanbecoming theory for nurses (Parse, 1998, 2007). Giorgi's method does allow for the analysis of one participant's description (Giorgi, 1075) to be viewed through the lens of a discipline in demonstrating the analysis from the participant's words to a higher level of abstraction in the language of science. We will do so with Parse's (1998) humanbecoming theory; Parse's (1998, 2007) humanbecoming school of thought has underpinnings in the human science tradition, with a focus on quality of life from the indivisible, unpredictable, everchanging human's perspective.

The humanbecoming theory was carefully designed including assumptions, principles, concepts, paradoxes, and postulates (Parse, 2007). Humanbecoming theory creates opportunities for nurses to view, and live, their nursing care from a different perspective than that of the medical sciences where individuals are seen as a sum of their parts (Parse, 1998). We are utilizing this unique perspective as a guide in our research study development and analysis of data descriptions of the lived experience of persons with type 1 diabetes.

\section{RESEARCH QUESTION}

The research question giving direction for this research is: What is the meaning of the lived experience of newly diagnosed young adults and their family members who live with type 1 diabetes?

\section{DATA DESCRIPTION COLLECTION}

Giorgi's (2009) method allows for the use of technology for data collection, thus enabling young adults and their family members to participate via email from anywhere in the world they may be. Participants (individuals who are 18-24 years and their family members) are being sought through internet support groups and recruitment notices. They are invited to write a description of their experience living with type 1 diabetes and to send it to the lead researcher via email employing techniques to allow for anonymity. The study has been passed through two ethical review boards at the University of New Brunswick, in Fredericton, New Brunswick, Canada.

\section{ANALYSIS OF THE DATA DESCRIPTION}

To date, we have only one description. It is very poignant. Since Giorgi's (2009) method also allows for an analysis using one or more descriptions, we decided to perform an analysis on this one data description. The analysis involves a process which may appear linear, but is not. It involves the following steps, however noting that we have only considered the first 4 steps in this analysis. When we have further participants, we will engage in step 5.

1. Contemplative dwelling with the descriptions

2. Identifying meaning units (MUs): MUs are expressed in the participants' words. 
3. Identifying focal meanings (FMs): FMs are written at a higher level of discourse (to the abstract) in the language of the researcher. Parse (1986) articulated the transposition from the language as being an intuitive leap (Santopinto, 1987),

4. Synthesizing a situated structural description (SSD) for each participant. The SSD is synthesized from each participant's set of FMs (Giorgi, 1975). It is the meaning of the lived experience for each individual participant.

5. Synthesizing a general structural description (GSD) of all participants' SSDs (Giorgi, 1975). The GSD is the meaning of the lived experience from the perspective of all participants.

We will present the entire data description in italics from one young adult who lives with type 1 diabetes (the third author of this paper-Allison), then follow it with a sample of the steps of analysis.

\section{My Baby Bird- Living with Type 1 Diabetes}

Living with type 1 diabetes is like caring for a baby bird. One day, out of nowhere, you find it. You're not really sure what to do with it, but you know you have to do something-it is a life or death situation. The baby bird is so needy...it requires constant attention. If, even for second, you stop thinking about it, it will start chirping madly until you give it the attention it craves. You learn something new every day about how to take care of it. It likes one type of food one day and doesn't like it the next. Every day is a struggle to keep that baby bird alive, but you know that it's worth it. Yet, no matter how much you love it and care for it, there is always a chance it will fall off its perch and break its neck.

I was diagnosed when I was 18 years old- a freshman at university studying Kinesiology. It was my first time living on my own, so of course I thought all the crazy symptoms I was having were due to my new lifestyle. I believed I was dehydrated from walking to class. That had to be why I was drinking over 4 litres of water a day...right? Obviously I had to pee so much because of all that water I was drinking. And my eye sight was getting worse because I needed a new prescription for my glasses, that's all. It took about two months to realize that taking a bottle of juice into the shower (so I wouldn't drink the water), and eating snow on my way to work to quench my never-ending thirst wasn't normal. I thought about all the weird things that had been happening to me in the last two months and came up with thirteen abnormal symptoms that I had been experiencing. I looked them up on the Internet and one word came up. A word that means a lot more to me now than it did then: Diabetes.

I talked to my parents and we decided that I should go to the campus health centre. I was very stressed about having to miss class to go, but at our health centre, it was first-come, first-served so I couldn't make an appointment for later in the day. My sister came with me, but I ended up having to wait so long that she had to get to class, so I was alone. I sat there, watching the clock tick by; watching people that had come after me go in first. Had I signed in properly? Did they skip me? Did I miss when they called my name? I was in a very emotional state. Finally, after an hour and a half, they called me in. I saw a nurse who listened to my symptoms and wrote notes. She told me that the doctor would be able to see me at lunch. I left with no new information, possibly more questions than before.

When I saw the doctor, I told her that I thought I had diabetes. I listed off my symptoms again. She stopped me to ask some questions.

"Do you ever think of killing yourself?"

No.

"Do you think your boyfriend is cheating on you?"

No.

"I think you are just stressed and need to see a psychologist. Promise me you'll make an appointment at Counselling Services."

Great, now I feel like crap AND I'm crazy.

More confused than ever, I left again.

Two days later, I was at the Health and Wellness Fair for one of my classes. Some first year nursing students were performing health screenings. I had to have one done for my class, so my friend and I went and found some nurses. 
It was what you would expect: blood pressure, height, weight, BMI, eating patterns, sleeping patterns, exercise....then came blood sugar. She asked if it would be okay if she checked my blood sugar. I shrugged, not really sure what that meant. She got out this huge, archaic machine and pricked my finger. She expertly placed a Band-Aid on my finger while the machine took a good 5 minutes to produce a reading. When it beeped, she looked at it, confused. She apologized and asked if she could do 'It' again, saying that it didn't work. I supplied her yet another drop of blood, and got another Band-Aid in return. When the machine beeped again, she said she just had to see her teacher for a minute. Her instructor came over and explained that my blood sugar was 30.9 (over 6 times what the normal level is). She suggested I go to the health clinic, I said, "I'm not going there again, they think I'm crazy", so she said that I should go to the hospital instead and told me that security would take me and my friend.

I had never been to an emergency room before. The triage nurse checked my blood sugar, saying this probably wouldn't be the last time I'd prick my finger. I didn't even see the inside of the waiting room...I was sent right to a bed. My sister arrived a couple of hours later, having heard from my parents, who I had called on the way. The doctor came back into the room and said it:

\section{"You have type 1 diabetes" \\ That's when I found my baby bird.}

It is now three years later and I think I have been successful in overcoming this obstacle. I got a pump 6 months in. It was the best decision of my life. Wearing my pump, which I playfully refer to as "Piper" (from the word 'diabetes, meaning 'pipe-like'), has become second nature. Most people don't even notice it, or at least they don't talk about it.

That is one thing that I've noticed: people seem afraid to talk about my diabetes. Or maybe they don't care, which is why I don't tend to bring it up unless the situation/conversation calls for it. It's as if people worry that I will get upset if they ask about it. It's not a secret: I'm diabetic. Children, however, have no problem pointing to my pump and asking "why do you wear that?" I've even had kids try to press the buttons! I take each opportunity to teach the people around me what it is that I am living with, and what it means.

My biggest struggle with type 1 diabetes is not the high and low blood sugars, the carb counting, wearing my pump $24 / 7$, or the worry in the back of my mind that every night when I go to sleep, I might not wake up. It's the ignorance of others that makes having type 1 diabetes hard.

Only about $10 \%$ of diabetics are type 1. This means that most of the general population hears about type 2 which, I hate to admit, carries a certain stigma with it. People do not know that type 1 is an autoimmune disorder that cannot be avoided. It has nothing to do with eating too much sugar or not exercising. Being an adult when diagnosed with juvenile diabetes didn't help either. A big problem is that type 2 diabetics aren't even educated on the difference between type 1 and 2. We are our only advocates! On numerous occasions, I have had type 2 diabetics (and one pre-diabetic) tell me that "I know EXACTLTY what you're going through". This is not true. I have a baby bird; they have an elderly cat that keeps a low profile until it is hungry or sick.

Their ignorance is not their fault. Remember when I said I took a Bachelor's degree in Kinesiology? I took a lot of health courses in my undergrad. All throughout my degree, only twice were type 1 and 2 differentiated (one of those times because my professor asked me to explain it to the class). Most professors throw a huge blanket over diabetes... and this is in a health science field! I actually had a professor say that type 1 was a congenital disorder that strictly prohibits the 'sufferer' from certain foods. I usually never raise my hand in class, but felt obligated for my fellow dia-buddies to correct her. I told her (and the class) that with all the new technologies type 1 diabetics are actually free to eat just about anything. She responded with "I'm going to have to disagree with you". I fought back and can only hope the class learned something about type 1 that day. I am now studying at Chiropractic College to become a doctor and, in case you're wondering, no one here differentiates type 1 and 2 either.

Most days I don't really notice my diabetes but every so often I stop and think "When did this happen?" It's weird to me, knowing that when people hear about diabetes they may think of me, because when I think of myself, it's the last thing on the list. Some days I don't feel like I have enough time to be diabetic. Site changes take about 5 
minutes, but I put them off until my reservoir is empty because I don't have the time to 'waste'. There are all kinds of websites and technology that you can use to help you keep track of your disease and keep better control, but for me, I am a person first and a diabetic second. As long as my sugars are okay and my AlC is normal, I just keep doing what I'm doing. Maybe this is because I found my baby bird so late in life. I am happy to care for it, but I still want to be the same person I was before. One good thing about having diabetes is that I am more conscious of my health and what goes into my mouth. I think this will be good for me in the long run.

It seems like every time I turn around, there is something new to help control diabetes. I can't keep up with it. I'm very happy with my pump. Someday, though, I do hope for a cure, so I will be able to teach my baby bird to fly and set it free.

\section{Analysis-Synthesis}

Below is an example of three meaning units (written in the participant's words) which are each followed with the analysis to focal meanings (written in the researchers' words).

\section{Meaning Unit 1}

Living with type 1 diabetes is like caring for a baby bird. One day, out of nowhere, you find it. You're not really sure what to do with it, but you know you have to do something-it is a life or death situation. The baby bird is so needy...it requires constant attention. If, even for second, you stop thinking about it, it will start chirping madly until you give it the attention it craves. You learn something new every day about how to take care of it. It likes one type of food one day and doesn't like it the next. Every day is a struggle to keep that baby bird alive, but you know that it's worth it. Yet, no matter how much you love it and care for it, there is always a chance it will fall off its perch and break its neck.

\section{Focal Meaning 1}

The lived paradox of being-non being emerges as Allison presents a unique metaphor of caring for a precious, helpless, living being representing what it is like for her to live with type 1 diabetes.

\section{$\underline{\text { Meaning Unit } 5}$}

When I saw the doctor, I told her that I thought I had diabetes. I listed off my symptoms again. She stopped me to ask some questions.

"Do you ever think of killing yourself?"

No.

"Do you think your boyfriend is cheating on you?"

No.

"I think you are just stressed and need to see a psychologist. Promise me you'll make an appointment at Counselling Services."

Great, now I feel like crap AND I'm crazy.

More confused than ever, I left again.

\section{Focal Meaning 5}

For Allison having her perspective disregarded along with an unjustified diagnosis by a physician surfaced bewildering feelings of disillusionment with medicine and self-doubt.

\section{Meaning Unit 11}

It seems like every time I turn around, there is something new to help control diabetes. I can't keep up with it. I'm very happy with my pump. Someday, though, I do hope for a cure, so I will be able to teach my baby bird to fly and set it free. 


\title{
Focal Meaning 11
}

\author{
is nonexistent.
}

In the emerging now, Allison is content with the status quo, while dreaming of a future where her diabetes

In Giorgi's method, all of the focal meanings are joined together to become the situated structural description (SSD) for Allison; noting that the SSD is written at a higher level of discourse utilizing humanbecoming theory and is considered Allison's meaning of living with type 1 diabetes.

\section{Situated Structural Description for Allison}

The paradox of being-non being emerges as Allison presents a unique metaphor of caring for a precious, helpless, living creature representing what it is for her to live with type 1 diabetes. While coming to discover that she lives with diabetes Allison had mixed feelings of explicit knowing-tacit knowing of symptoms with believingnot believing it could actually happen to her. It was in collaboration with family members regarding her symptoms that led her to seek health care direction. Clinic routines may have been known to others, yet the uncertainty of processes created anxiety, feelings of solitude, and expressions of emotions for Allison whilst sharing her perspective with healthcare professionals. For Allison having her perspective disregarded along with an unjustified diagnosis by a physician surfaced bewildering feelings of disillusionment with medicine and self-doubt. While two days later having confirmation of her distressing symptoms by a young professional and then again by more seasoned professionals along with the diagnosis of type 1 diabetes was vindicating. At present for Allison, thriving and using technology is effortless as she embraces living with type 1 diabetes appreciating the benefits-costs of focusing on dietary intake amidst the extra time required for self-preservation. When called for, she assiduously advocates for those who live the experience amidst the ignorance and misunderstandings of others. In the originating of conforming-not conforming, for Allison, having diabetes is not 'how' she wishes to be known to others nor is it prominent when she perceives herself. In the unfolding of the emerging now, Allison is content with the status quo, while dreaming of a future where her diabetes is non-existent.

\section{DISCUSSION}

No phenomenological studies could be found to date describing the lived experience of young adults living with type 1 diabetes. Some literature has been found which relates to components of our analysis. For example, Allison described the symptoms that led her and her family to decide that she needed to seek medical assessment. She described the impact that her diagnosis had on her and what it is like teaching others about type 1 diabetes. These findings have similarities and differences with findings presented by Damião \& Pinto (2007), who found when analyzing qualitative interviews from adolescents between the ages of 14 and 18 that three themes surfaced. The first theme was "learning about the diagnosis" and included the following: "presenting signs and symptoms; experiencing the impact of diagnosis; and learning about diabetes" (p. 570). Allison described the experience of not being heard by health care professionals, and what it was like to be disregarded as well as feeling vindicated when a diagnosis was finally made. She also wrote that she wonders, "When did this happen?" when she stops to really ponder her experience. Allison described learning about diabetes in the early phases of her experience as depicted in her metaphor of caring for her baby bird and learning something new every day. Interestingly, she also described more of a role of teaching others to enhance their understanding which began early in her experience. We see this as a leap from gaining knowledge to giving it-which could be perhaps related to the fact that she was diagnosed during her young adulthood, rather than when she was a child or adolescent as in Damião \& Pinto's study.

Normalcy is a concept found in the literature when researching perceptions of living with type 1 diabetes. Balfe (2009) described young adults experiencing "a tension between being healthy and being normal" (p. 128). While, another study by Marshall et al., (2009) described "every child, every parent and every family created and strove (to a greater or lesser degree) to place diabetes into the background of their lives to achieve what they wanted, which was a "normal life"' (p. 1709). Allison described successfully overcoming this obstacle and not wanting to be known or remembered because of her diabetes whilst wanting to be the same person she was before. She described her insulin pump as being the best decision of her life and second nature to her in helping her to maintain her normalcy. 
Parse $(1998,2007)$ described meaning, rhythmicity, and transcendence as themes in her humanbecoming theory. From Allison's description, we can see the meaning that she has attributed to her experience in having embraced the requisites for keeping herself alive in her metaphorical expression of 'keeping her baby bird from breaking its neck', as well as the fact that she does not consider 'being diabetic' when she thinks about who she is as a person. Allison lives the paradoxical rhythms of: being-non-being; believing-not believing; benefits-costs; explicit knowing-tacit knowing; and conforming-not conforming in her lived experience with type 1 diabetes. She has also described transcendence in her expression of appreciating the benefits of maintaining a healthy lifestyle while hoping for a cure so that she can 'set her baby bird free'.

\section{CONCLUSION}

We are thankful for Allison's contribution to this paper. We will continue with our research data collection and analyze data descriptions as they are received. We will also include data descriptions of our own experiences being family members of a person who lives with diabetes and synthesize them with Allison's situated structural description. We will present our perspectives separately from other family members at first, then follow by including them in another analysis of all research data descriptions to become the general structural description or the meaning of family members living with type 1 diabetes. We hope that this paper has enhanced the reader's understanding and illuminated what it is like for one young adult to live with type 1 diabetes.

\section{AUTHOR INFORMATION}

Dr. Catherine Aquino-Russell, RN, BScN, MN, Ph.D. completed a Bachelor of Nursing Science, Lakehead University, Thunder Bay, Ontario; a Masters in Nursing, University of Manitoba, Winnipeg; a Diploma in University Teaching, University of New Brunswick, Fredericton, New Brunswick, Canada; and a Ph.D. in Nursing, Curtin University, Perth, Western Australia. She has held numerous education, leadership, volunteer, and administration positions in hospitals and universities in Canada and Indonesia. At present, she holds the positions of Full Professor and BN Program Director at the Faculty of Nursing, University of New Brunswick, Moncton Campus, in Moncton, New Brunswick, Canada. E-mail: caquinor@unb.ca (Corresponding author)

Dr. Roger Russell, BSc (Agr), MBA, Ph.D. holds a Science degree (Agricultural Economics), University of Guelph, Guelph, Ontario; a Master of Business Administration (Management), Saint Mary's University, Halifax, Nova Scotia, a Diploma in University Teaching, University of New Brunswick, Fredericton, New Brunswick, Canada; and a Ph.D. in Business (International Management), Curtin University, Perth, Western Australia. Roger has been employed in several industries (agricultural, foodservice, banking, international development, and post secondary education) while working in five Canadian provinces and three countries (Canada, Indonesia, and Haiti). Currently, Roger is a professor, researcher, and administrator (Director of Professional Studies Division) at Crandall University, in Moncton, New Brunswick Canada. E-mail: roger.russell@crandallu.ca

Allison Russell, BSc Kinesiology completed her Bachelor of Science in Kinesiology, University of New Brunswick, Fredericton, New Brunswick. She is presently working on her Doctor of Chiropractic degree, New York Chiropractic College, Seneca Falls, New York. Allison has two published fictional pieces: The Monster Within, published by Young Writers of Canada (2006) and Every Time I Die, published by Xlibris (2009). E-mail: allisonmrussell@studentmail.nycc.edu

Catrina Russell, BSc Geology completed her Bachelor of Science in Geology, University of New Brunswick, Fredericton, New Brunswick. She is presently completing her Masters of Science in Geology-Space Sciences, University of New Brunswick. She attended the International Space University (summer, 2012), Florida State University, Melbourne, Florida. E-mail: catrina.elen@gmail.com

\section{REFERENCES}

1. Balfe, M. (2009). The body projects of university students with type 1 diabetes. Qualitative Health Research, 19(1), 128-139. 
2. Canadian Diabetes Association. (2009). Diabetes Facts. Retrieved from: http://diabetes.ca/aboutdiabetes/what/facts/DiabetesFacts

3. Damião, E., \& Pinto, C. (2007). Being transformed by illness: Adolescents' diabetes experience. Rev Latino-am Enfermagem julho-agosto, 15(4), 568-74.

4. Giorgi, A. (2009). The descriptive phenomenological method in psychology: A modified Husserlian approach. Pittsburg, PA: Duquesne University Press.

5. Giorgi, A. P., \& Giorgi, B. M. (2003). The descriptive phenomenological psychological method. In P. M. Camic, J. E. Rhodes \& L. Yardley (Eds.), Qualitative research in psychology: Expanding perspectives in methodology and design. Washington, DC: American Psychological Association.

6. Giorgi, A. (1975). An application of phenomenological method in psychology. In A. Giorgi, C. Fischer \& E. Murray (Eds.), Duquesne studies in phenomenological psychology (Vol. II). (Chapter 6, pp. 82-103). Pittsburgh: Duquesne University Press.

7. Isenberger, K. (2008). Journey of hope: A Katy family copes with type 1 diabetes. Retrieved from: http://www.katymagazine.com/articles/2008/winter/type-1-diabetes-14.pdf

8. Karvonen, M., et al. (2000). Incidence of childhood type 1 diabetes worldwide. Diabetes Care, 23(10), 1516-1526.

9. Marshall, M., Carter, B., Rose, K., \& Brotherton, A. (2009). Living with type 1 diabetes: Perceptions of children and their parents. Journal of Clinical Nursing, 18, 1703-1710.

10. Parse, R. R. (1998). The humanbecoming school of thought for nurses and health care professionals. Thousand Oaks, CA: Sage.

11. Parse, R. R. (2007). The humanbecoming school of thought in 2050. Nursing Science Quarterly, 20(4), 308-311. doi: 10.1177/0894318407307160

12. Parse, R. R. (1986). The phenomenological method, (Cassette Recording No. D11-202 A \& B). Pittsburgh.

13. Santopinto, M. D. A. (1989). The relentless drive to be ever thinner: A study using the phenomenological method. Nursing Science Quarterly, 2(1), 29-36.

14. Wennick, A., \& Hallström, I. (2007). Families' lived experience one year after a child was diagnosed with type 1 diabetes. Journal of Advanced Nursing, 60(3), 299-307.

15. Wennick, A., \& Hallström, I. (2006). Swedish families' lived experience when a child is first diagnosed as having insulin-dependent diabetes mellitus: An ongoing learning process. Journal of Family Nursing, 12, 368-389.

16. Wennick, A., Lundqvist, A., \& Hallström, I. (2009). Everyday experience of families three years after diagnosis of type 1 diabetes in children: A research paper. Journal of Pediatric Nursing, 24(3), 222-230. 